\author{
FEDERAL RESERVE BANK OF SAN FRANCISCO \\ WORKING PAPER SERIES
}

\title{
The Unemployed with Jobs and without Jobs
}

\author{
Robert E. Hall \\ Hoover Institution and Department of Economics Stanford University \\ Marianna Kudlyak \\ Federal Reserve Bank of San Francisco
}

February 2022

Working Paper 2021-17

https://www.frbsf.org/economic-research/publications/working-papers/2021/17/

\section{Suggested citation:}

Hall, Robert E., Marianna Kudlyak. 2022 "The Unemployed with Jobs and without Jobs," Federal Reserve Bank of San Francisco Working Paper 2021-17. https://doi.org/10.24148/wp2021-17

The views in this paper are solely the responsibility of the authors and should not be interpreted as reflecting the views of the Federal Reserve Bank of San Francisco or the Board of Governors of the Federal Reserve System. 


\title{
The Unemployed with Jobs and without Jobs *
}

\author{
Robert E. Hall \\ Hoover Institution and Department of Economics \\ Stanford University \\ rehall@stanford.edu; stanford.edu/ rehall \\ Marianna Kudlyak \\ Federal Reserve Bank of San Francisco \\ Hoover Institution, IZA and CEPR \\ marianna.kudlyak@sf.frb.org; www.mariannakudlyak.com
}

February 15, 2022

\begin{abstract}
Potential workers are classified as unemployed if they seek work but are not working. The unemployed population contains two groups - those with jobs and those without jobs. Those with jobs are on furlough or temporary layoff. This group expanded tremendously in April 2020, at the trough of the pandemic recession. They wait out periods of non-work with the understanding that their jobs still exist and that they will be recalled. We show that the resulting temporary-layoff unemployment mostly dissipated by the end of 2020. Potential workers without jobs constitute what we call jobless unemployment. Shocks that elevate jobless unemployment have much more persistent effects. Historical major adverse shocks, such as the financial crisis in 2008, created mostly jobless unemployment and consequently caused extended periods of elevated unemployment. Jobless unemployment reached its pandemic peak in November 2020, at $4.9 \%$, modest by historical standards, and has declined at a faster-than-historical pace since.
\end{abstract}

JEL: E32, J63, J64.

Keywords: Business cycle, Recovery, Unemployment, Recession, Layoffs, Temporary Layoff, Recall

${ }^{*}$ Hall's research was supported by the Hoover Institution. The opinions expressed are those of the authors and do not reflect those of the Federal Reserve Bank of San Francisco or the Federal Reserve System. We thank Benjamin Schoefer and David Wiczer for helpful discussions and anonymous referees for useful suggestions. We thank Varsha L. Appaji for excellent research assistance. 


\section{Contents}

1 Introduction $\quad 3$

2 Related Research $\quad 6$

3 Measuring Temporary-Layoff and Jobless Unemployment $\quad 8$

4 Temporary-Layoff and Jobless Unemployment before and during the Pan$\begin{array}{ll}\text { demic } & 9\end{array}$

4.1 Pre-Pandemic . . . . . . . . . . . . . . . . . . . . . . . 9

4.2 March-April 2020 . . . . . . . . . . . . . . . . . . . 10

4.3 April-November 2020 . . . . . . . . . . . . . . . . . . 10

4.4 November 2020 -December $2021 \ldots \ldots$. . . . . . . . . . . . 10

4.5 The pandemic cohort . . . . . . . . . . . . . . . . 12

5 Labor Market Tightness 14

5.1 The work-finding rate . . . . . . . . . . . . . . . . . . . 14

5.2 Vacancy-unemployment ratio . . . . . . . . . . . . . . . . . 19

5.3 Labor market perceptions . . . . . . . . . . . . . . . . . . . 22

5.3 .1 Consumer perceptions . . . . . . . . . . . . . . 22

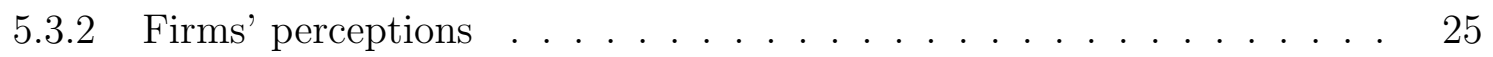

6 The Distinction between Temporary-Layoff and Jobless Unemployment 25

6.1 Measuring the expectation of recall from employer data . . . . . . . . . . . . 27

6.2 Recalls before the pandemic . . . . . . . . . . . . . . . . 28

6.3 Recalls in the pandemic . . . . . . . . . . . . . . . . . . . . . . 29

6.3.1 Information content of declared recall likelihood . . . . . . . . . . . 29

6.3.2 Evidence on recalls without conditioning on expectation . . . . . . 29

7 Social Costs of Temporary-Layoff and Jobless Unemployment 30

8 Concluding Remarks $\quad 31$ 


\section{Introduction}

The global pandemic has led to unemployment of catastrophic proportions in the United States. From February to April of 2020, the unemployment rate spiked from 3.5 percent to 14.7 percent. In May 2020, a recovery began, and by November the unemployment rate declined by 8 percentage points. For comparison, during the recovery from the 2007-09 recession, it took ten years for total unemployment to decline by 6.5 percentage points. In December 2021, unemployment was only 0.4 percentage points above its pre-pandemic level. The recovery of the US unemployment rate has been vastly speedier than its historical pace.

We argue that a key to understanding unemployment in the pandemic is distinguishing between the unemployed without jobs and the unemployed with jobs. Our main findings are

- First, the pandemic shock caused an outburst of unemployment of a different kind than any other recessionary shock.

- Second, this kind of unemployment-temporary-layoff unemployment-recovers at a much faster pace than a typical jobless unemployment, because most of these unemployed are indeed recalled and the time-consuming search and matching process that impedes a quick recovery is avoided.

- Third, despite a large social cost of total unemployment, the labor market during the pandemic remained relatively tight.

In the labor-force statistics of the United States, an individual is unemployed if not working, but available for work, and either actively looking for work or on temporary layoff, waiting to return to an existing job. We refer to the latter category of unemployment as temporary-layoff unemployment and to the rest of unemployment - as jobless unemployment.

A major difference between temporary-layoff and jobless unemployment is that temporarylayoff unemployment returns to normal much faster than does jobless unemployment. A decline in temporary-layoff unemployment takes place as economic conditions improve and firms recall workers. No search or matching is involved; firm-worker match capital is preserved. In contrast, a decline in jobless unemployment takes time. Creation of new, stable, firm-worker relationships is a long and costly process. Terminated workers often circle through a number of short-term jobs before finding a stable job (Hall and Kudlyak (2019)).

Until the pandemic hit the labor market in March 2020, the great majority of the unemployed fell into the jobless category (those actively looking for work), and only a fraction of one percent of the labor force was on temporary layoff. Unemployment was effectively synonymous with joblessness. Aligning with this conception, most of the search and matching models and concepts in labor economics have been designed to study jobless unemployment. 
In contrast to the previous recessions, which destroyed jobs, the pandemic prevented many millions of individuals from working, but they retained their jobs. We find that during the pandemic recession, the entire increase in the total unemployment rate from February to April came from temporary-layoff unemployment. The huge cohort of layoffs into temporary-layoff unemployment in April 2020 also accounted for most of the incidence of temporary-layoff unemployment afterwards.

Temporary-layoff unemployment also accounted for the entire rapid decline in total unemployment from its peak in April through November 2020. Jobless unemployment was, in fact, increasing during this period, reaching its peak in November 2020 at 4.9 percent and starting its recovery thereafter. In previous recessions, the recovery of total unemployment started with the recovery of jobless unemployment, and both glided downward at a constant proportional rate of approximately 10 percent per year (Hall and Kudlyak (2020)). We find that the decline of jobless unemployment from its pandemic peak in November 2020 has been three times faster so far than its historical pace.

The condition of the labor market can be characterized by how tight or slack the market is for the jobless unemployed. Despite high overall unemployment rates early in the pandemic, the labor market remained reasonably tight during the pandemic. Prior to the pandemic, the overall unemployment rate was a reasonable guide to job-finding rates throughout the labor market. By that standard, the labor market in November 2020, with overall unemployment at 6.7 percent, was slack. In historical times when unemployment was that high, jobs were hard to find. We show that the job-finding rate for the jobless unemployed fell in April 2020 but bounced back later. In November 2020, the job-finding rate among the jobless unemployed was at the level similar to the average rates in 2015 and 2016, when total unemployment was $5.3 \%$ and $4.9 \%$, respectively. We note that when using unemployment to measure labor-market tightness in times of unusual volumes of temporary-layoff unemployment, it is appropriate to use the unemployment rate for jobless unemployed in place of the overall unemployment rate. We also argue that total unemployment is not an appropriate denominator in the vacancy-unemployment measure of labor market tightness, because vacancy measures do not take into account the retained jobs of the temporarily laid off workers.

Because a substantial fraction of workers on temporary layoff do not search, but rather return to their existing jobs, we generalize the concept of job-finding to encompass recall. We call the general process work-finding. For the jobless unemployed, the work-finding rate is synonymous with the job-finding rate, but for the unemployed on temporary layoff, the workfinding rate is considerably higher than the job-finding rate because it includes recalls. As in the pre-pandemic period, during the pandemic, the work-finding rate among the temporary- 
layoff unemployed was twice as high as the rate among the jobless unemployed. This also held true for the unemployed at durations of six months or longer.

Our distinction between temporary-layoff and jobless unemployment is based on the expectation of recall while unemployed rather than on the outcome of recall after the fact. Recall expectations evolve over an individual's unemployment spell, and the self-reported reason for unemployment may change. Not all individuals on temporary layoff return to their previous jobs. Some may become jobless unemployed, find new jobs, or leave the labor force. Conversely, as time passes, individuals not classified earlier under temporary-layoff unemployment may learn that they do have a possibility of recall and thus be reclassified as in temporary-layoff unemployment. The classification based on contemporaneous selfreported reason for unemployment captures expectation of recall, which in turn influences action such as search and saving behaviour.

We note that, in the regime created by a pandemic, total unemployment retains its social significance even though a high fraction of the unemployed have retained their jobs. The overall unemployment rate remains an appropriate measure of idled labor input and lost employment income. Higher temporary-layoff unemployment implies a burden on the economy from the decline in the utilization of available labor and a corresponding decline in the earnings of the labor force. However, there is a partially offsetting social benefit from the increased time available for household activities and the preservation of job-specific human capital among workers who do return to their previous jobs.

This paper is about unemployment, but we should note that the pandemic resulted in a substantial decline in the labor force as well. Expansion of unemployment and of the population outside the labor market was accompanied by contraction in employment. In February of 2020, 36.6 percent of the working-age population was out of the labor force, neither working nor unemployed. The fraction out of the labor force rose by 1.9 percentage points to 38.5 percent in November 2020 and remained high. The rise in the population out of the labor force in recessions is rarely this big. For example, in the recession that began in December 2007 and ended in June 2009, the fraction out of the labor force rate only rose by 0.3 percentage points. Analysis of the social consequences of the rise in the fraction of the population not in the labor force arising from the pandemic would proceed in parallel to the analysis of the rise in the unemployment rate.

It is clear that, first, firms found themselves needing to lay off a large number of workers abruptly at the onset of the pandemic shock, they also anticipated recalling them on an equally large scale, contrary to the economic circumstances surrounding previous recessions. This is evident from the abrupt explosion of mass temporary layoffs (Kudlyak and Wolcott 
(2020)). Second, recalls indeed happened on a large scale. While we do not provide direct measures of recalls, we cite evidence from other studies that confirm this point.

The findings in this paper show that it is vital to distinguish between temporary-layoff and jobless unemployment in modeling the pandemic labor market and the effects of the policies to ameliorate the impact of the pandemic. Lee, Park and Shin (2021) use our classification into jobless and temporary-layoff unemployment to study an unequal employment effects of the pandemic. Gertler, Huckfeldt and Trigari (2021) adopt our terminology of jobless and temporary-layoff unemployment in their quantitative model of unemployment dynamics and use the model to study the effect of the pandemic and evaluate the Paycheck Protection Program. Giupponi, Landais and Lapeyre (forthcoming) use the distinction between jobless and temporary-layoff unemployment in their analysis of social insurance policies in the pandemic.

The rest of the paper is structured as follows. Section 2 describes related literature. Section 3 describes how we measure temporary-layoff and jobless unemployment in the Current Population Survey. Section 4 describes temporary-layoff and jobless unemployment before and during the pandemic. Section 5 examines work-finding rates and labor-market tightness. Section 6 discusses the distinction between temporary-layoff unemployment and

jobless unemployment based on expectation ex ante of recall. Section 7 discusses social costs of temporary-layoff and jobless unemployment.

\section{Related Research}

Our paper focuses on the implications of the distinction between temporary layoffs versus unemployment for other reasons for the dynamics of the labor market. In this section, we describe some of the related research. We also cite other research later in the paper.

Feldstein (1976) launched an extensive literature on the role of temporary layoffs in labor dynamics. He found that an imperfect experience rating system in which firms did not pay the full cost of benefits accounted for a large portion of temporary layoffs and the resulting bulge in unemployment in a recession. Other work on this issue includes Topel (1983), Card and Levine (1994), Brown and Ferrall (2003), and Ratner (2014). Fujita and Moscarini (2017) study recalls, which is defined as the unemployed worker's return to the previous employer, regardless of the expectation of the return at the time of layoff. They demonstrate the importance of recall in pre-pandemic data and find that post-unemployment outcomes for recalled workers were substantially better than for those not recalled, a finding consistent with ours using pandemic data. 
A number of empirical papers, using various sources, have documented that the onset of the pandemic recession was characterized by an outburst of temporary layoffs. Bartik, Bertrand, Lin, Rothstein and Unrath (2020) document that the share of the unemployed who were on temporary layoff rose to nearly 80 percent in April 2020. Hedin, Schnorr and Wachter (2020) and Bell, Hedin, Moghadam, Schnorr and Wachter (2021), using administrative records from the California unemployment insurance system, find that over $90 \%$ of new claimants in late March 2020 in California reported that they expected to be recalled to their prior jobs, up from around $40 \%$ in February, and that the share expecting recalls steadily declined over the next few months.

Gregory, Menzio and Wiczer (2020) is a mainly theoretical paper that is complementary to this paper. It emphasizes heterogeneity in the job-search process, including especially the difference between searchers with a prospect for recall and those without that prospect. The paper calibrates the model to the differing experiences of those groups and from other dimensions of heterogeneity in pre-pandemic data. It characterizes the central issue as the difference between a favorable $\mathrm{V}$-shaped recovery, where the high re-employment rate of recalled workers dominates the recovery, and an unfavorable L-shaped recovery, where job losers undergo a time-consuming process finding new, stable jobs. With the pandemic-period data we assemble in this paper, the model can be calibrated more directly to the pandemic, and, based on results to date, would probably portray a more favorable recovery than Gregory and co-authors develop. Buera, Fattal-Jaefz, Hopenhayn, Neumeyer and Shin (2021) calculate how long it would take the economy to recover after social distancing restrictions were lifted. A key assumption underlying the quick post-shutdown recovery is that workers who have been temporarily laid off in the shutdown can return to work without going through the normal hiring market. Our paper provides support for their assumption. Leyva and Urrutia (2021) study temporary layoffs in a model with informal labor markets in times of the pandemic in Latin America.

Gallant, Kroft, Lange and Notowidigdo (2020) build a detailed model of labor-market transitions based on distinguishing individuals by layoff status. The model's calibration is confirmed by studying pandemic-period data through July. A main thrust of the paper is the finding that the demand assumptions fed into the model forecast much less unemployment than do professional forecasters. Forsythe, Kahn, Lange and Wiczer (2020) investigate labormarket tightness in the first six months of the pandemic, distinguishing job-seekers who are expecting recall from those not expecting recall using vacancy data from Burning Glass Technologies. 


\section{Measuring Temporary-Layoff and Jobless Unemploy- ment}

The Current Population Survey (CPS), designed and published by the Bureau of Labor Statistics (BLS), is the basis for the official estimates of the unemployment rate and related measures of labor-market status. We use the CPS to study temporary-layoff and jobless unemployment, and other related issues.

In the CPS, an individual is unemployed if they did not work during the week containing the 12th of the month, were available for work, and either actively searched for work or expected to be recalled to their previous job. Unemployed people are asked further questions to determine if their unemployment is a result of temporary layoff, other kinds of job loss, completing a temporary job, recently entering the labor force, reentering the labor force, or quitting a job. The CPS uses the term "layoff" to describe temporary layoffs and terms "other job loser" to describe layoffs without expectation of recall.

Unemployed people are classified in the CPS as being on temporary layoff if "...they are waiting to be recalled to a job from which they were temporarily separated for businessrelated reasons such as temporary drops in demand, business downturns, plant remodeling, material shortages, and inventory taking. They must have been given a date to report back to work or, if not given a date, must expect to be recalled to the job within 6 months." (U.S.Census (2013)). The CPS states that because a person reported to be on layoff may not meet the official definition as stated above, the interviewers ask additional questions to determine whether the individual expects to be recalled to the job. These questions are "Has your employer given you a date to return to work?" and "Have you been given any indication that you will be recalled to work within the next 6 months?" An answer "yes" to either of these questions leads to classification of the person as being on temporary layoff (U.S.Census (2013)). ${ }^{1}$

We classify the unemployed into temporary-layoff and jobless unemployment based on their self-reported reason for unemployment in the CPS. The temporary-layoff unemployed

\footnotetext{
${ }^{1}$ There was a small change in the interviewing process for the CPS in March-April 2020 that might have led to a larger fraction of layoffs to be counted as temporary as compared to the previous periods. In the "Frequently asked questions" supplement to the Employment Situation for April 2020 (BLS (2020)), the BLS mentions that because of the unusual circumstances related to the pandemic, additional guidance was provided to household survey interviewers regarding the question "Have you been given any indication that you will be recalled to work within the next 6 months?" If, because of the coronavirus, a person was uncertain of when they would be able to return to work and thus was unsure of how to answer the question, the interviewer was instructed to enter a response of "yes," rather than "don't know." We do not anticipate that this change in the interviewing protocol changes the key conclusions of the paper. Below we cite evidence that workers who were classified as laid off without recall returned to their previous employers at higher rates than before pandemic.
} 
are those who report being on temporary layoff. The jobless unemployed are the rest of the unemployed - those who report being unemployed due to other job loss, completing a temporary job, recently entering the labor force, reentering the labor force, or quitting a job.

There is another category closely related to unemployment in the CPS, which covers individuals who are employed but are absent without pay. Members of this category are not counted in the official unemployment statistics, even though the BLS indicated that some of them should be counted (BLS (2020)). Only in the pandemic has this category had a meaningful number of members. It is likely that a significant fraction of the individuals assigned to this category were effectively temporary-layoff unemployed (BLS (2020)). None of the conclusions of this paper would be much affected by adding all of the members of this category to our measure of temporary-layoff unemployment, though the rate would be higher by several percentage points in the early months of the pandemic.

\section{Temporary-Layoff and Jobless Unemployment be- fore and during the Pandemic}

We calculate the temporary-layoff unemployment rate and the jobless unemployment rate by dividing the total number of the unemployed in each category by the labor force. The aggregate unemployment rate is the sum of the temporary-layoff unemployment rate and the jobless unemployment rate. We report seasonally adjusted numbers unless stated otherwise. ${ }^{2}$

\subsection{Pre-Pandemic}

Figure 1, panel (a), shows the temporary-layoff and jobless unemployment rates from January 1965 through December 2021. Until February 2020, the last month before the pandemic influenced the labor market, temporary-layoff unemployment was modest in relation to jobless unemployment at all times. When the labor market was strong and unemployment low, the temporary-layoff portion was under one percent of the labor force, while jobless unemployment only dropped below four percent in the strongest years. In recessions, jobless unemployment rose to close to 9 percent of the labor force. In the recessions starting in 1974 and 1981, temporary-layoff unemployment touched 2 percent, but hardly rose at all in the

\footnotetext{
${ }^{2}$ To construct the temporary-layoff and jobless unemployment rates, we use the seasonally adjusted counts of the unemployed in the temporary-layoff and other categories for reasons for unemployment, respectively, from the BLS. Because the sum of the seasonally adjusted counts in separate categories do not add up exactly to the seasonally adjusted count of the total number of the unemployed individuals reported by the BLS, the sum of the seasonally adjusted temporary-layoff unemployment rate and the jobless unemployment rate differs slightly from the official unemployment rate, with the discrepancy raging from -0.21 percentage points in March 1975 to 0.30 in September 1975 during 1967-2021.
} 
later recessions of 1990 and 2001. Even the severe recession starting in 2007 saw an increase in the temporary-layoff unemployment rate of less than one percentage point.

\subsection{March-April 2020}

Figure 1, panel (b), displays the data from January 2019 through December 2021. It portrays the totally different behavior of the two kinds of unemployment during the pandemic, starting in March 2020 when there was an abrupt burst of temporary layoffs on a mass scale. At the peak in April, the temporary-layoff unemployment rate had skyrocketed to 11.5 percent (from 0.5 in February 2020), constituting 78 percent of total unemployment. The jobless unemployment rate rose only slightly, to 3.2 percent from its February value of 3.0 percent. Temporary-layoff unemployment accounted for almost the entire increase in unemployment at the beginning of the 2020 pandemic.

\subsection{April-November 2020}

Immediately after reaching its peak in April 2020, the overall unemployment rate started declining in May of 2020 (Figure 1, panel (b)). During the first seven months, through November, the unemployment rate declined by 8 percentage points. The decline of overall unemployment since its recession peak was much faster than its decline during the previous recoveries.

From April to November 2020, temporary-layoff unemployment declined by 9.8 percentage points, accounting for more than the entire decline in total unemployment. Historically and in the pandemic, as we show in the sections below, the unemployed on temporary layoff have much higher job-finding rates than the jobless unemployed. This is one of the reasons behind the faster-than-historical recovery pace of the overall unemployment rate in the first months of the labor market recovery from the pandemic recession. From April to November 2020, the share of temporary-layoff unemployment in total unemployment declined from $78 \%$ to $26 \%$.

From April to November 2020, jobless unemployment was, in fact, gradually increasing, reaching its pandemic peak in November 2020. In November, temporary-layoff unemployment was 1.75 percent and jobless unemployment was 4.9 percent, adding up to total unemployment of 6.7 percent.

\subsection{November 2020-December 2021}

Jobless unemployment started its recovery in November 2020. From November 2020 to December 2021, jobless unemployment declined from $4.9 \%$ to $3.4 \%$. 


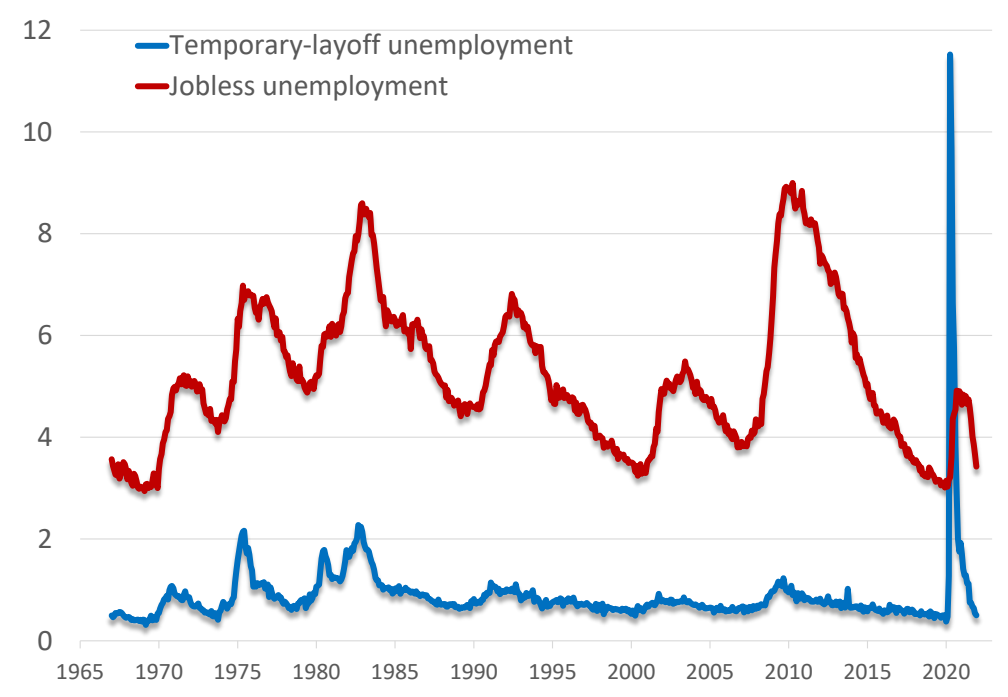

(a) $1967-2021$

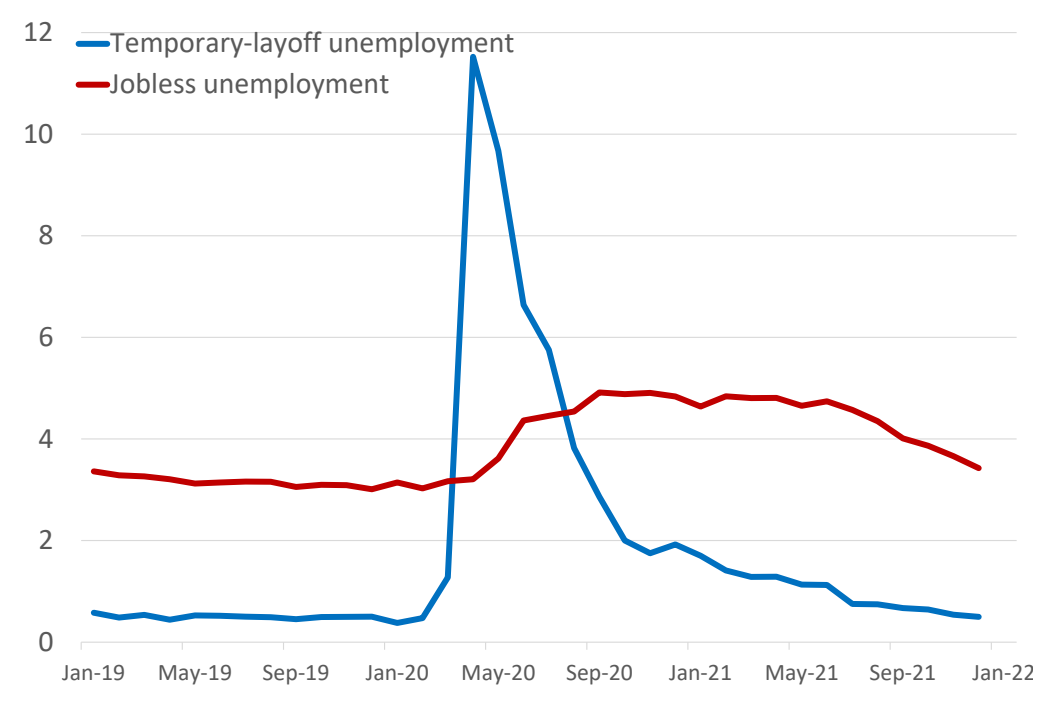

(b) 2019-2021

Figure 1: Temporary-Layoff Unemployment Rate and Jobless Unemployment Rate

Note: Temporary-layoff unemployment is unemployment on layoff with expectation of recall. Jobless unemployment is unemployment for other reasons. The two kinds of unemployment add up to the total unemployment rate. The series are expressed as percentages of the labor force and are seasonally adjusted. Data through December 2021. Data source: CPS. 


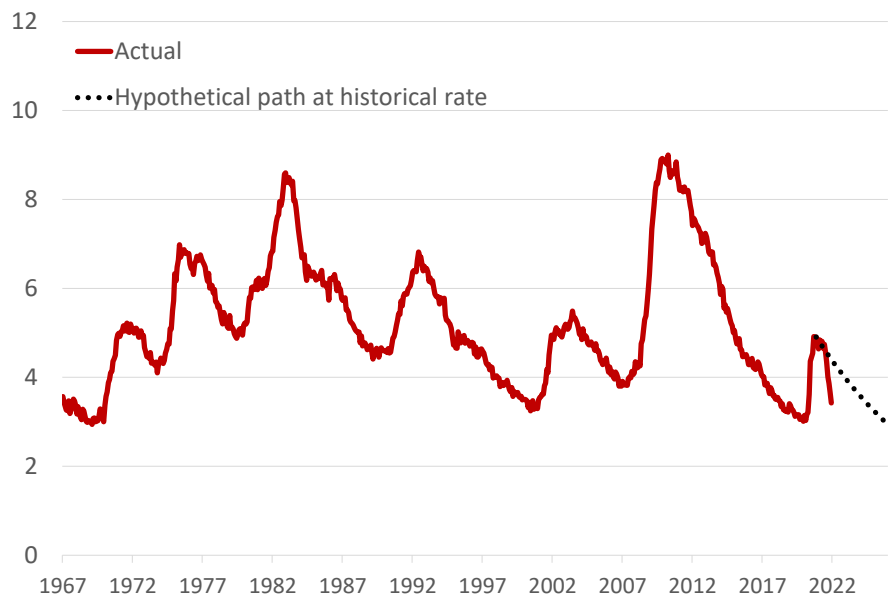

Figure 2: The Jobless Unemployment Rate, Actual and Hypothetical Based on the Historical Rate

Note: Jobless unemployment is unemployment for reasons other than temporary layoff. The series are expressed as percentages of the labor force and are seasonally adjusted. Source: Authors' calculations using data from the CPS. Data extend through December 2021.

Figure 2 shows the actual jobless unemployment rate and the hypothetical path of jobless unemployment from its peak in November 2020 at its historical rate of 10 percent per year as estimated in Hall and Kudlyak (2020) (dotted black line). We find that the recovery rate of jobless unemployment from its pandemic peak in November 2020 has been three times faster, so far, than its historical pace.

Summarizing, in December 2021, the aggregate unemployment rate at 3.9\% was only 0.4 percentage points higher than its pre-pandemic level, with the entire difference coming entirely from jobless unemployment as temporary-layoff unemployment was at its pre-pandemic level. Such a fast recovery of unemployment, by historical standards, was associated with the rapid recovery of temporary-layoff unemployment during the first seven months, and later with a faster-than-historical pace of jobless unemployment recovery.

\subsection{The pandemic cohort}

Figure 3 shows the temporary-layoff unemployment rate by length of spell, from January 2020 to December 2021. We use non-seasonally adjusted numbers for this figure to focus on the short two-year period and avoid any distortions from the seasonal adjustment applied to 


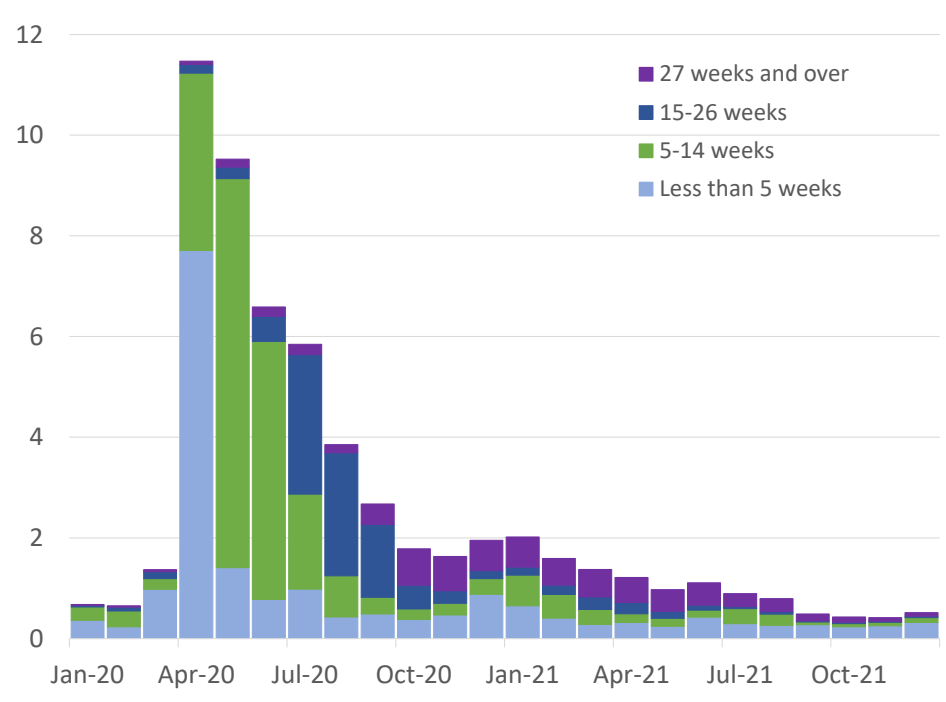

Figure 3: Temporary-Layoff Unemployment by Duration, as Percent of Labor Force Note: The CPS data, monthly, non-seasonally adjusted. Data through December 2021.

the unprecedented changes in the series. ${ }^{3}$ In Figure 3, the lowest duration category, less than 5 weeks, serves as a measure of new layoffs into temporary-layoff unemployment. The figure makes it clear that there was a huge pulse of layoffs in April 2020, amounting to almost 8 percent of the labor force. Layoffs in later months were nowhere near as high. In May 2020, most of the workers on layoff had been laid off in April; new layoffs were low. That category also includes workers laid off in March and a few in February 2020. The big lump from April also showed up in June and July in the 5 to 14 week category. By August, the lump had moved into the 15 to 26 week category. It was still visible at the end of 2020 in the $27+$ weeks category, but by then, most of the lump had been recalled, had found jobs, or moved to jobless unemployment.

Figure 3 shows that the fraction of the temporary-layoff unemployed with longer-duration increased during the year. In November 2020, the temporary-layoff unemployed with duration of 6 months or longer constituted 42 percent of all temporary-layoff unemployed individuals. It is, perhaps, surprising that workers unemployed for longer than 6 months were still counted as on temporary layoff. But this is consistent with the CPS's definition of temporary layoffs. Workers on layoff who have been given an indication that they will

\footnotetext{
${ }^{3}$ For example, Bartik et al. (2020) report all statistics as not seasonally adjusted stating that neither multiplicative nor additive seasonal adjustment procedures are appropriate to an unprecedented situation.
} 
be recalled to work within the next 6 months from the time of the interview are counted as being on temporary layoff.

The huge wave of layoffs into temporary-layoff unemployment in April 2020 also accounted for most of the incidence of temporary-layoff unemployment afterwards. After May 2020, additional workers who were laid off with indications of recall constituted at most $1 \%$ of the labor force. In Section 5, we examine their rates of returning to employment, and, in Section 6 , we cite evidence that many of these returns were recalls to the previous employers.

\section{$5 \quad$ Labor Market Tightness}

One of the important contributions of the models of the labor market associated with Diamond, Mortensen, and Pissarides (DMP) is the formalization of the concept of tightness. The market is tight when people find work easily and quickly, and employers locate new workers with difficulty and slowly. The job-finding rate is one of the key metrics of tightness in the DMP framework. It is the probability that a non-working individual in a given month will be working in the following month. Given our emphasis on the distinction between temporary-layoff and jobless unemployment, we refer to the work-finding rate rather than the job-finding rate. The unemployed on temporary layoff do not necessarily look for jobs, as they have one from which they believe they are temporarily separated. The temporary-layoff unemployed seek to find work, often at their previous jobs. The work-finding rate can be measured directly from the CPS microdata. Note that it includes the probability that the worker will take a new job rather than wait for recall to an existing job.

The vacancy-unemployment ratio is the other key metric of labor-market tightness. We

use data on vacancies at businesses from the Job Openings and Labor Turnover Survey (JOLTS).

\subsection{The work-finding rate}

The work-finding rate is the probability that a person, observed in a given non-working status in one month, is working in the following month. In tight labor markets with overall unemployment rates below 4 percent, the typical work-finding rate is roughly double its value in the worst slumps. Put another way, it takes twice as long to find work than it does when the labor market is strong.

One important question about the pandemic labor market is how tight or slack the market was for the jobless unemployed. For the jobless, the work-finding rate is the job-finding rate. 
We measure the work-finding rate using the CPS micro data. ${ }^{4}$ We merge monthly basic CPS files month-to-month using Shimer (2012) algorithm, construct the monthly work finding rate series for the unemployed on temporary layoff and the jobless unemployed using sampling weights, and seasonally adjust the series. ${ }^{5}$

Figure 4 shows work-finding rates for people in the two categories of unemployment considered in this paper. Panel (a) shows rates in the full sample. The upper line is the frequency that a person in temporary-layoff unemployment in one month is working in any job in the following month. Such a person was either recalled or took a new job. The lower line shows the job-finding rate, the frequency with which a person in jobless unemployment in one month is working in the following month. The work-finding rate out of temporarylayoff unemployment is about double the job-finding rate for those in jobless unemployment. Both rates track the business cycle and were at high levels at the beginning of 2020 .

Panel (b) of Figure 4 shows what happened in the pandemic. While prior to the pandemic, the work-finding rates of the temporary-layoff and jobless unemployed tracked the business cycle, the movements of the work-finding rates for the jobless unemployed and temporarylayoff unemployed diverged during the pandemic. The work-finding rate for temporary-layoff unemployed individuals fell in the months through November, relative to the average of the same months averaged over 2017, 2018, and 2019.

The work-finding rate for jobless unemployed people fell noticeably in April but, in contrast to the rate for the temporary-layoff unemployed, it bounced back in May. During the seven months after the unemployment peak in April 2020, the work-finding rate of the jobless unemployed was higher than would have been expected historically given the high level of the overall unemployment rate in those months. In November 2020, the seasonally adjusted work-finding rate from jobless-unemployment was 0.20. Most recently, the similar job-finding rate was in 2015 and 2016 - 0.20 and 0.21, respectively (measured as annual averages of monthly rates). In November 2020, total unemployment was $6.7 \%$, while jobless unemployment was $4.9 \%$. For comparison, in 2015, jobless unemployment was $4.7 \%$ (and total unemployment was 5.3\%), and in 2016, jobless unemployment was $4.3 \%$ (total unemployment was $4.7 \%$ ).

We note that when using unemployment to measure labor-market tightness in times of unusual volumes of temporary-layoff unemployment it is appropriate to use the unemploy-

\footnotetext{
${ }^{4}$ In the analysis, we calculate the work finding rate of the unemployed on temporary layoff and the jobless unemployed conditional on the respondent's classification into these categories in a given month. In Section 6 , we discuss that expectation of recall might evolve over the course of the unemployment spell.

${ }^{5}$ Following Shimer (2012), we treat missing observations as missing at random. Chodorow-Reich and Coglianese (2021) find that despite the much lower response rates of cohorts entering the CPS sample in March-August 2020, the unemployment rate in these cohorts looks similar to the overall unemployment rate.
} 


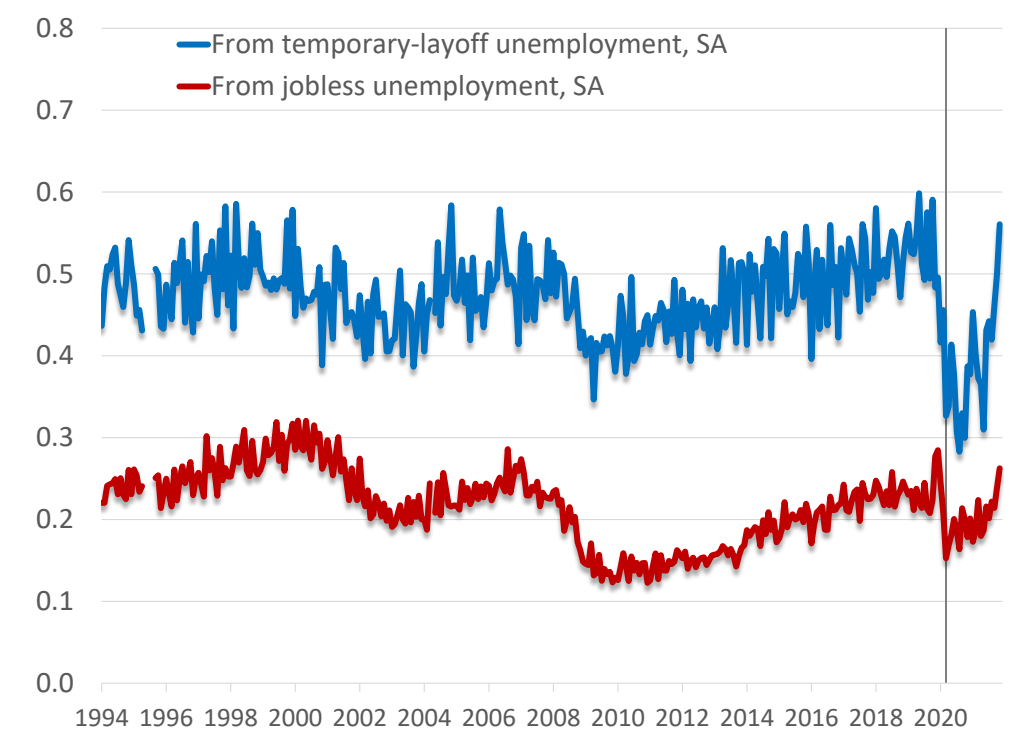

(a) $1994-2021$

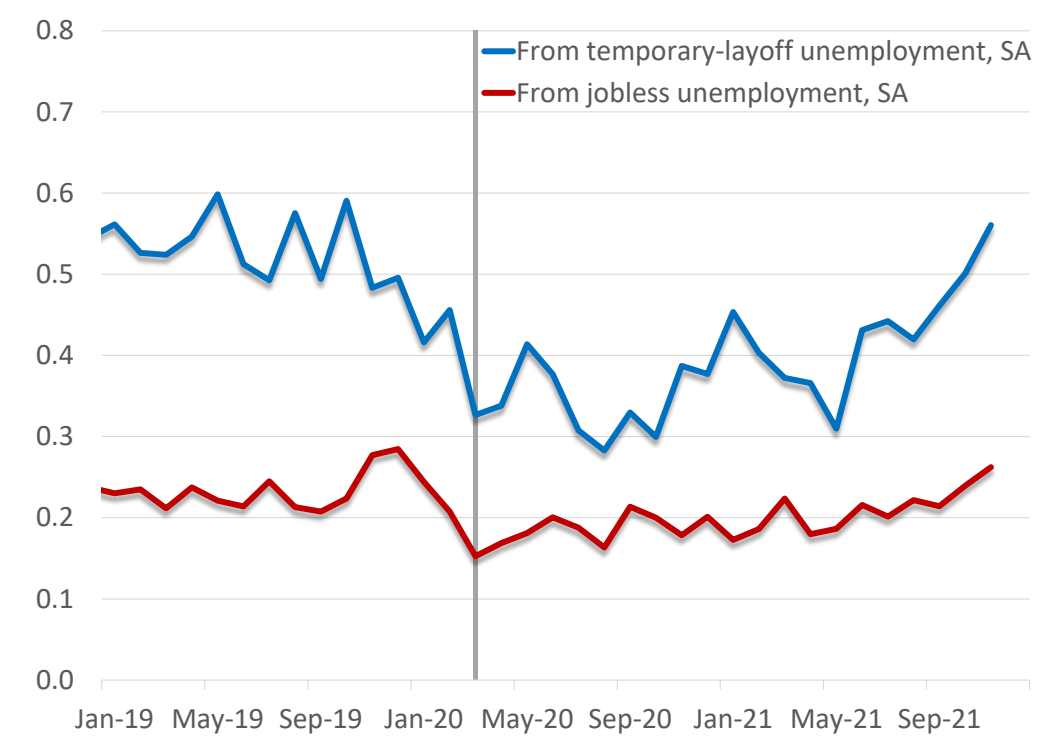

(b) 2019-2021

Figure 4: Work-Finding Rates for the Temporary-Layoff and Jobless Unemployed

Note: The figure shows the rate at which the unemployed transition into employment from one month to the next, with the later month labeled on the horizontal-axis. The series are monthly and seasonally adjusted using Shimer's (2012) seasonal adjustment procedure. The vertical line indicates April 2020. Data source: CPS micro data. Data through December 2021. 
ment rate for jobless unemployed in place of the overall unemployment rate. However, even when using the jobless unemployment rate as an indicator of labor market tightness, we find that the job-finding rate of the jobless unemployed during the pandemic was somewhat higher than would have been historically the case at $4.9 \%$ of jobless unemployment.

Figure 5 shows the work-finding rates of the temporary-layoff and jobless unemployed with durations less than one month (panels (a) and (c)) and durations longer than 6 months (panels (b) and (d)). The upper panels show the series over the full sample and the lower panels zoom out on the 2020-2021 period. Since the monthly job finding rates are quite volatile month-to-month, even seasonally adjusted, we show the series as the annual averages of the monthly series up to 2019, and monthly series thereafter.

As can be seen in Figure 5, the work-finding rate of short-term temporary-layoff unemployed dipped in April 2020 and recovered later. The work-finding rate of long-term temporary-layoff unemployed remained steady through 2020 and the first half of 2021 and started increasing in the second half of 2021. This category was small prior to the pandemic because rarely did the temporary-layoff unemployed remain in that state for longer than 6 months. ${ }^{6}$ The category exploded during the pandemic. In the CPS sample, the monthly counts of the unemployed respondents on temporary layoff with durations of 6 months and over were 25 and below until April 2020, between 50 and 66 in May-August, and reached 310 in September and 286 in October. A large fraction of individuals in temporary-layoff with long duration is another distinct feature of the pandemic.

Figure 5 demonstrates that the depressed average work finding rate of the unemployed on temporary layoff during 2020 and the first half of 2021 (as shown in panel (b) of Figure 4) reflects lower rates of those with longer duration. It appears that the pandemic cohort of individuals who were laid off with expectation of recall in April 2020 remained unemployed for longer than those who were laid off after April 2020.

In summary, during the pandemic, as in the pre-pandemic period, the work-finding rate among the temporary-layoff unemployed was twice as high as that among the jobless unemployed. This also holds true for the unemployed at durations of six months or longer. While the CPS data do not allow tracking recalls, in Section 6, we cite evidence that suggest that many of the unemployed who expected recall were indeed recalled. One might wonder to what extent relatively higher work-finding rates among the temporary-layoff unemployed is the result of the characteristics of the two kinds of unemployment. In Section 6, we cite evidence that a large number of temporarily laid-off workers during the pandemic were a

\footnotetext{
${ }^{6}$ We calculate the work finding rate only for the months with 10 or more unemployed respondents in the CPS sample.
} 


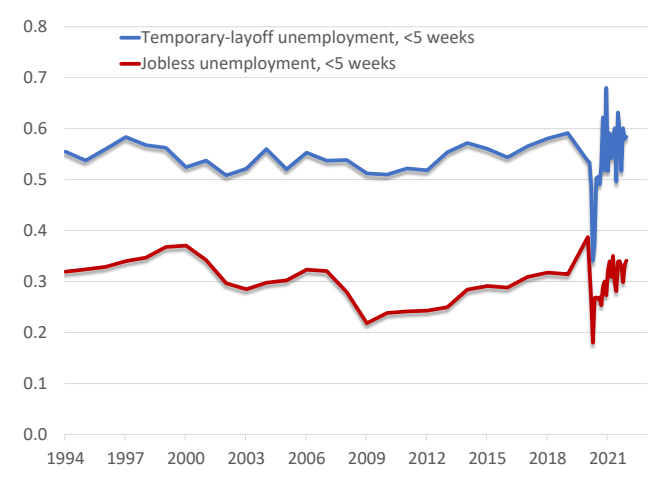

(a) The short-term unemployed, 1994-2021

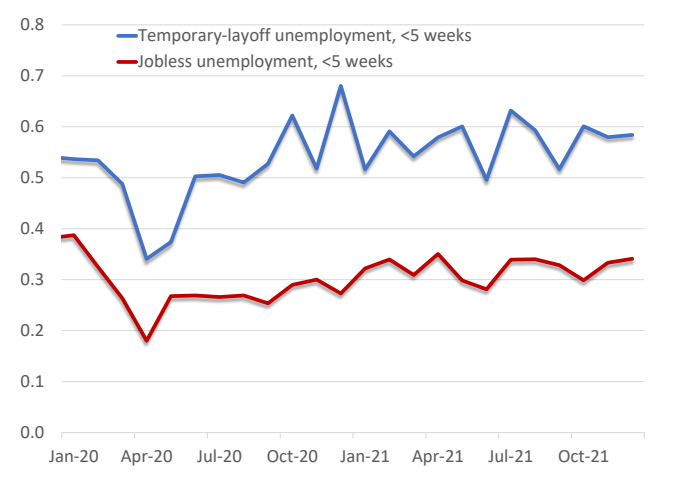

(c) The short-term unemployed, 2020-2021

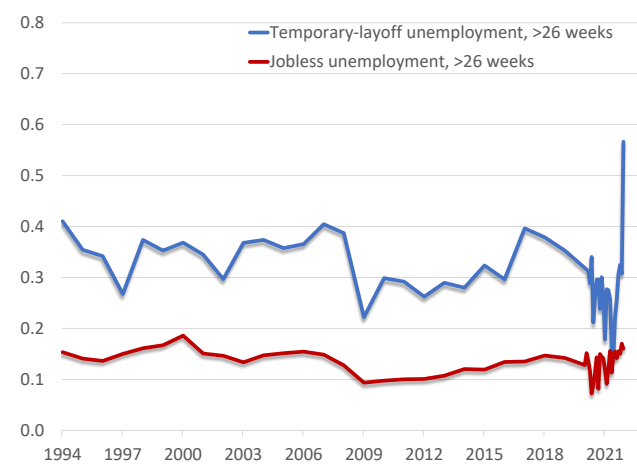

(b) The long-term unemployed, 1994-2021

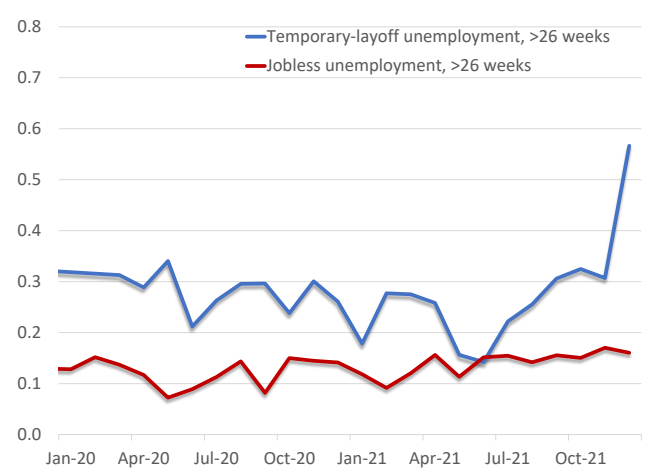

(d) The long-term unemployed, 2020-2021

Figure 5: Work-Finding Rates for the Temporary-Layoff and Jobless Unemployed, by Duration of Unemployment

Note: The figures show the rate at which the unemployed people transition into employment from one month to another, with the latter month labeled on the horizontal axis. The series are annual averages of the seasonally adjusted series up to 2019, and monthly series thereafter. The series are calculated only for the months with 10 or more unemployed individuals in the CPS sample. Data through December 2021. 
part of the mass layoff events and therefore not individually selected. Further research on this topic would be productive.

\subsection{Vacancy-unemployment ratio}

When the vacancy-unemployment ratio is low-vacancies are scarce while job-seekers are plentiful-jobs are hard to find and the labor market is slack. Alternatively, when the vacancy-unemployment ratio is high - vacancies are plentiful and job-seekers are scarcevacancies are hard to fill and the labor market is tight. That is, the vacancy-unemployment ratio is low in slumps and high in booms.

The appropriate measure of vacancies should include those vacancies that are available for any job-seeker and not those positions that are being held for the workers to be recalled. This is what JOLTS measures. The appropriate measure in the denominator of the vacancyunemployment ratio is only those job seekers who actively search for jobs, not those who are waiting for recall.

Some temporary-layoff unemployed people engage in search. The CPS contains information on whether the individuals who were laid off with expectation of recall have been looking for work during the last four weeks. Using this information, we split the counts of the unemployed individuals on temporary layoff into those who search and those who do not search. Figure 6 shows these counts as share of the labor force. In April 2020, the temporary-layoff no-search unemployment rate was $10.26 \%$ and the temporary-layoff search unemployment rate was $1.26 \%$.

Figure 7 shows the ratio of vacancies to jobless unemployment (burgundy line), the ratio of vacancies to overall search unemployment, which is the sum of jobless and temporary-layoff search unemployment, and the ratio of vacancies to total unemployment (dark gray line). During the pandemic, the vacancy/jobless-unemployment ratio dropped from 1.4 to 0.9 and recovered quickly reaching 2.0 in December 2021. The vacancy/total-unemployment ratio shows a more dramatic decline during the pandemic and a faster bounce back-it dropped from 1.2 to 0.2 and sharply bounced back, reaching 1.7 in December; however, this measure is not accurate because the denominator includes temporary-layoff unemployment while the numerator does not include any counterpart. The vacancy/total-search-unemployment ratio lies between the other two other ratios.

The vacancy/jobless-unemployment ratio shows that the decline of tightness during the pandemic was comparable to the decline in the 2007-09 recession. In July 2021, the tightness

measure surpassed its pre-pandemic level in February 2020. While in 2021 the measure is much higher than in the cyclical peak prior to the 2007-09 recession, a comparison over such 


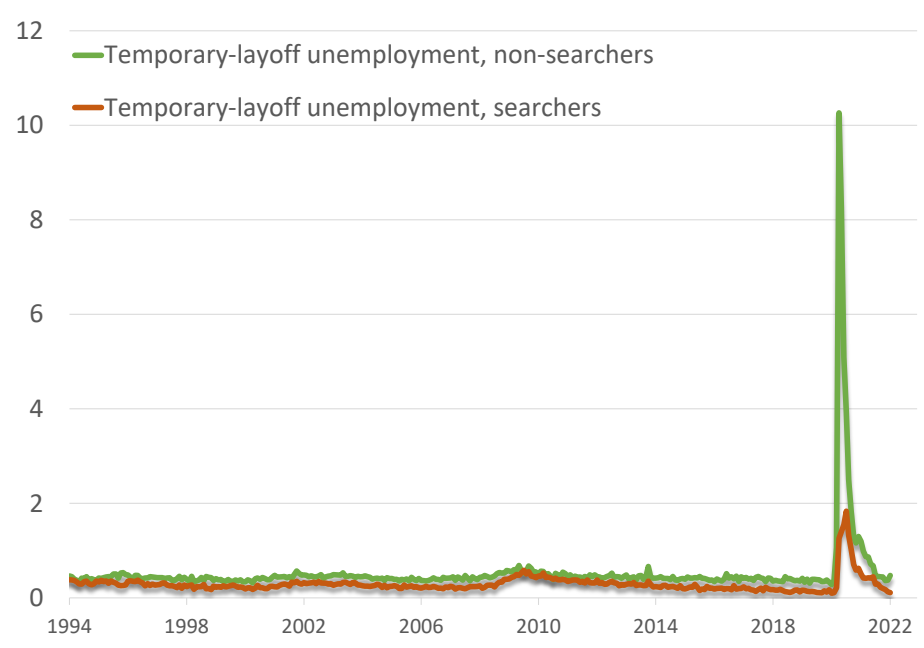

Figure 6: The Temporary-Layoff Unemployment Rate

Note: Data through January 2022.

an extended period might be hindered by long-run trends in the series (specifically, a trend in the vacancy series). ${ }^{7}$

Another measure of labor-market tightness is the average duration of a vacancy. It can be calculated as the ratio of the number of vacancies to the monthly flow of newly hired workers using data from JOLTS. However, JOLTS reports all new hires, without distinguishing recalls and new hires. Consequently, in the periods of high recalls as during the pandemic, one would require additional data to infer the number of rehires from total hires. We thus do not calculate the average duration of vacancy.

The Beveridge curve is a graph with unemployment on the horizontal axis and vacancies on the vertical axis. When the labor market is tight, vacancies are numerous and unemployment is low; the labor market is at a point up and to the left on the Beveridge curve. When the market is slack, vacancies are scarce and unemployment is high, down and to the right on the curve. Overall unemployment rose much more than would be consistent with the pre-pandemic Beveridge curve, given the behavior of vacancies. Jobless unemployment, when placed on the horizontal axis instead of overall unemployment, results in a reason-

\footnotetext{
${ }^{7}$ According to the tightness measure, the labor market was twice less tight in 2007 than in 2019. However, the job finding rates in 2019 were not higher than in 2007. In the basic DMP model, it is the level of tightness that determines the job finding rate; an enrichment of the model is needed to explain this observation.
} 


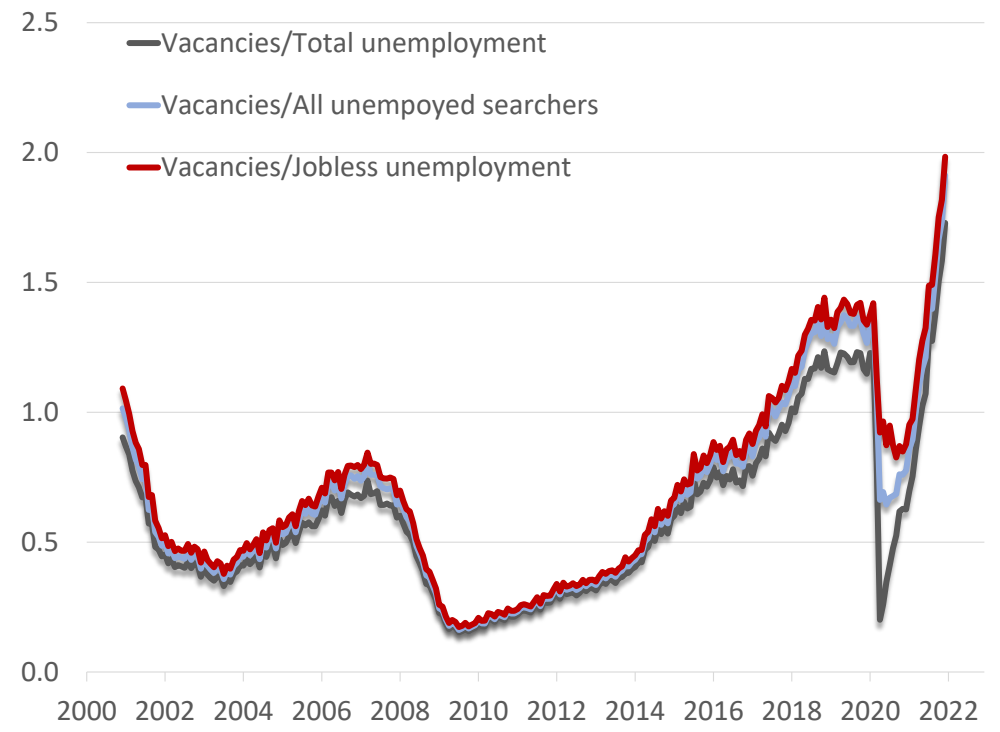

(a) Full sample

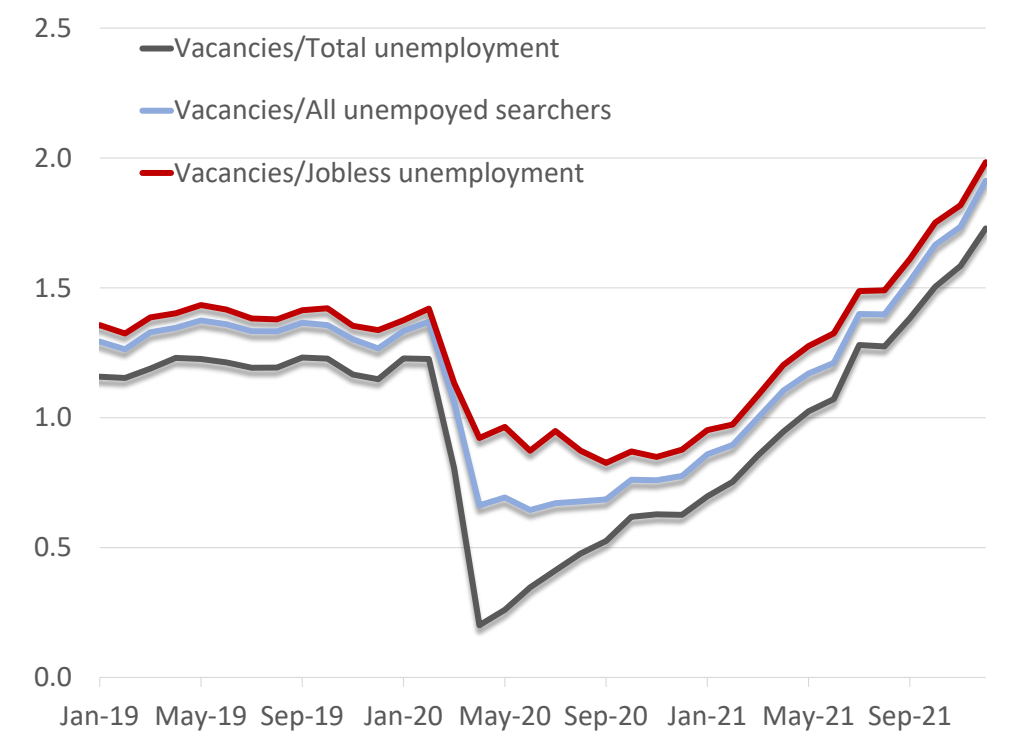

(b) 2019-2021

Figure 7: Vacancy-Unemployment Ratio

Note: Vacancy data from JOLTS. Unemployment data from the CPS. All series are seasonally adjusted. Data through December 2021. 
ably stable new version of the Beveridge curve (see, for example, Gallant et al. (2020)). Because the Beveridge curve uses the same data on job-seeking and recruitment as in the vacancy-unemployment ratio above, it would be redundant to present the data here in the Beveridge-curve format - it would not add to the strong case that jobless-unemployment plays a similar role in the pandemic labor market to the role that overall unemployment did in earlier recessions. Conceptually, we note that the Beveridge curve is inherently unstable, because, as embodied in the DMP model, the vacancy rate is a jump variable, whereas unemployment is a state variable that lags behind jumps in vacancies.

Summarizing, the measures of labor market tightness - the work-finding rate of the jobless unemployed and vacancy-to-jobless-unemployment or vacancy-to-search-unemployment ratio - show that the pandemic labor market was tighter than would be inferred from the overall unemployment rate. They agree that the labor market was less favorable for jobseekers than it was in the exceptionally strong market of 2019, but not as weak as the overall unemployment rate would suggest.

\subsection{Labor market perceptions}

\subsubsection{Consumer perceptions}

Consumer perceptions also indicate that the labor market has been tighter during the pandemic than suggested by the overall unemployment rate. We obtain the consumer perceptions data from the Conference Board, which conducts the Consumer Confidence Survey in which households are asked about their perceptions of the current business and employment conditions (as well as their expectations for six months hence regarding business conditions, employment, and income). Figure 8, panel (a) shows the share of the consumers who say that jobs are plentiful (the series "Present Situation: Employment Conditions: Jobs plentiful"), and panel (b) shows the share of the consumers who say that jobs are hard to get (the series "Present Situation: Employment Conditions: Jobs are hard to get"). The first measure is low when the labor market is weak and high when the labor market is strong, the opposite is true for the second measure. The series are monthly, June 1977 - January 2022, and are released at the end of a given month. ${ }^{8}$

\footnotetext{
${ }^{8}$ The Conference Board provides the following information about the data collection process: "The Consumer Confidence Survey is scheduled so that there are approximately 4 weekly waves conducted throughout a given month. Responses flow in throughout the collection period, with the sample close-out for preliminary estimates occurring about one week before preliminary results are released. Responses received after the cutoff date through the end of the month are used to produce the final estimates for the month, which are published with the release of the following month's data. The number of complete responses has been increased to 3,000 per month. In addition, the closing date for the preliminary findings has been extended and thus provides for broader coverage in a given month." See https://www.conferenceboard.org/pdf_free/press/TCB_CCS_TechNote_May2021.pdf.
} 


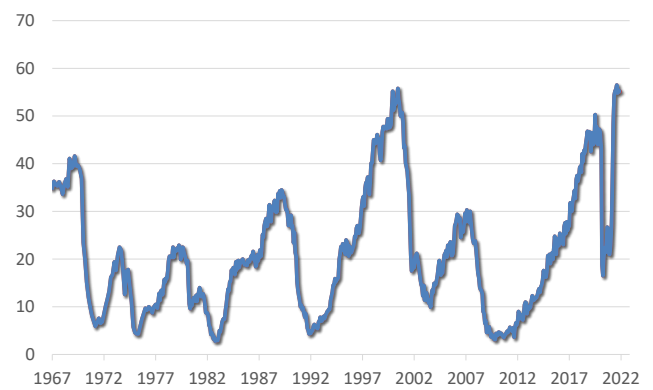

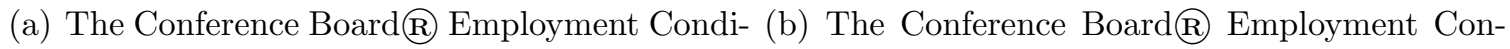
tions: Jobs plentiful

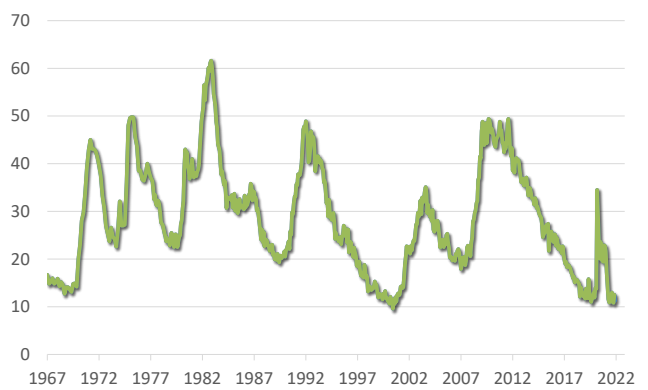

ditions: Jobs hard to get

Figure 8: Consumer Labor Market Perceptions

Note: The figure shows the shares of the consumers who say that jobs are plentiful (panel a) and the share of the consumers who say that jobs are hard to find (panel b). Data from the Conference Board@ through January 2022.

In June 2020, when the overall unemployment rate was 11\%, 23 percent of respondents said that jobs were hard to find. The most recent time when the unemployment rate came close to $11 \%$ was in October of 2009, when it reached its peak of $10 \%$ in the 2007-09 recession. At that time, $49 \%$ of respondents said that jobs were hard to find. Clearly, in June 2020, consumers did not perceive the labor market as weak as the $11 \%$ overall unemployment would historically indicate.

Weidner and Williams (2011) document that the labor market perceptions index, which they construct from the Conference Board survey as a diffusion index of percentage of households that think jobs are plentiful versus the percentage of households that think jobs are hard to get (\%plentiful - to get +100$)$, has been closely related to labor market slack. The high value of the index is associated with the strong labor market. To examine the relation in the pandemic, Figure 9 shows a scatter plot of monthly observations of the overall unemployment rate and the jobless unemployment rate (on the y-axis) against the labor market perceptions index (on the x-axis). We separately color-code observations from the pre-pandemic period (June 1977 - February 2020) and from the pandemic period (March 2020- December 2021).

Pre-pandemic, there was a downward-sloping relationship between the overall unemployment rate and the labor market perceptions index (blue dots in Figure 9), akin a Beveridge curve. After February 2020, this relationship altered as the labor market perceptions index 


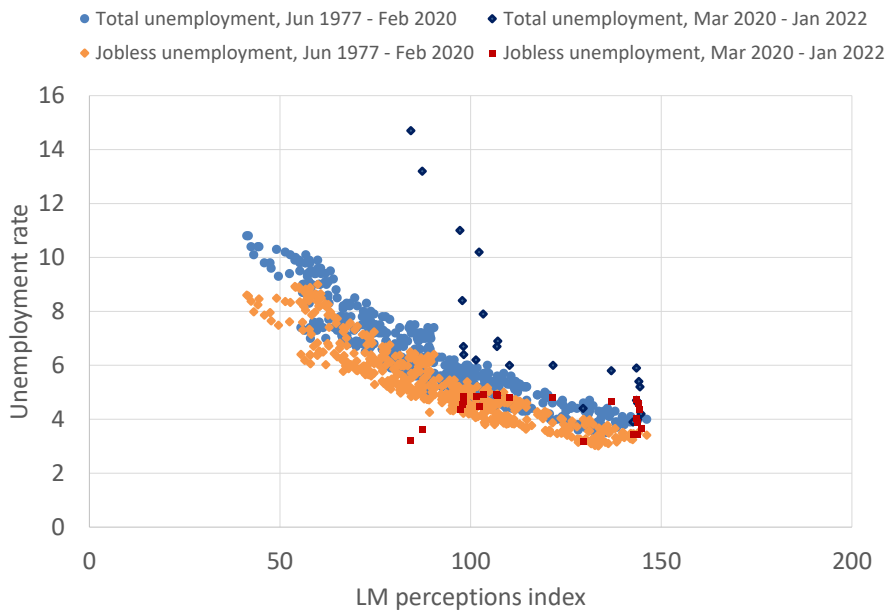

Figure 9: Consumer Labor Market Perceptions and Unemployment

Note: The labor market perceptions index is the percent of the consumers who say that jobs are plentiful minus the percent of the consumers who say that jobs are hard to find, plus 100, constructed from the Conference Board data. Data through January 2022.

remained nearly unchanged but the overall unemployment rate rose to historically high levels (dark blue dots).

We then examine the relation between the labor market perceptions index and the jobless unemployment rate. These are orange and red dots in Figure 9, representing the prepandemic (June 1977 - February 2020) and pandemic (March 2020- December 2021) periods, respectively. Given the pre-pandemic relation between the index and the overall unemployment rate, it is not surprising that pre-pandemic, there was a tight negatively-sloping relationship between the jobless unemployment rate and the labor market perceptions index as well (orange dots). In March and April 2020, the jobless unemployment was lower for a given level of the labor market perceptions index than historically was the case (the two red dots below the orange dots). Put differently, in March-April 2020 consumers perceived the labor market as worse than the level of contemporaneous jobless unemployment would have indicated historically. This is not surprising as March-April 2020 was the onset of the pandemic, characterized by mass, but to a large degree temporary, layoffs (Kudlyak and Wolcott (2020)). After April 2020, the red dots generally lay within the historical relationship between the perceptions index and the jobless unemployment rate. 


\subsubsection{Firms' perceptions}

In Figure 10, we examine labor market perceptions from the firm side. Panel (a) shows the series for the percentage of firms with "Jobs not Able to Fill Right Now" from the National Federation of Independent Business Research Foundation, which we obtain from the Conference Board. The level of the series is high when labor market is tight (panel (a)). The series dipped sharply at the onset of the pandemic but recovered quickly. Two observations stand out. First, the share of firms that found it had hard to fill jobs did not drop as low during the pandemic recession as in the previous business cycle troughs. Specifically, in May 2020, at the lowest reading of the series in the pandemic recession, $23 \%$ of firms responded that they found it hard to fill jobs, while during the 2007-09 recession the share of firms dropped to $7 \%$ in August 2009. Second, during the recovery from the pandemic recession, the share of firms finding it hard to fill jobs has risen to the levels not observed before. Specifically, in the tight labor market of 2019, at most $39 \%$ of firms found it hard, while $51 \%$ found it hard in September 2021.

The relation between unemployment and the percentage of firms finding it hard to fill jobs is shown in Figure 10, panel (b). Pre-pandemic, there was a close negative relation between the overall unemployment rate and the series (blue dots) (see Weidner and Williams (2011) for documenting this observation in the pre-2010 data); however, after February 2020, the relation broke, with overall unemployment being higher than historically was the case

for a given level of firms finding it hard (red dots). In contrast, the relation between the jobless unemployment and the percentage of firms which had hard-to-fill jobs is much closer through the entire sample period (green dots for the pre-pandemic period, and purple dots afterwards). In the post-February 2020 period, the series of the percentage of firms finding it hard extends further to the right, indicating that the percentage of firms finding it had hard reached historically high levels, which suggests a tight labor market.

Summarizing, these findings suggest that there is a closer association between jobless unemployment and labor market perceptions than between the overall unemployment rate and the perceptions, with the exception of the onset of the pandemic in March-April 2020.

\section{The Distinction between Temporary-Layoff and Job- less Unemployment}

The distinction between temporary-layoff unemployment and jobless unemployment in our paper is based on the expectation of recall while an individual is not at work. Recall expectations evolve over an individual unemployment spell, and the self-reported reason for 


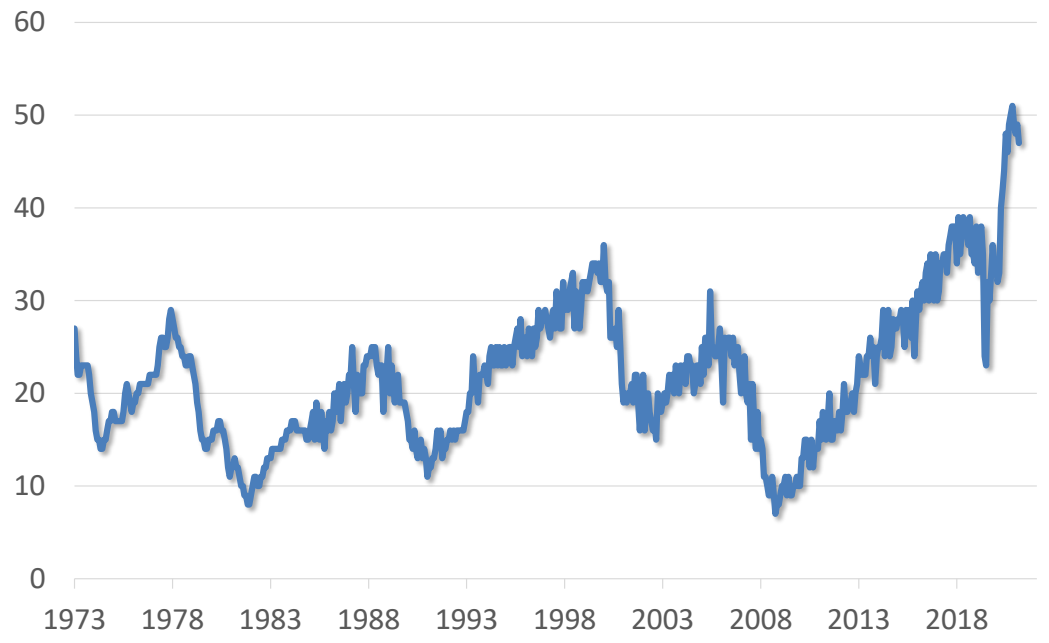

(a) Percentage of Firms with Jobs Not Able to Fill Right Now

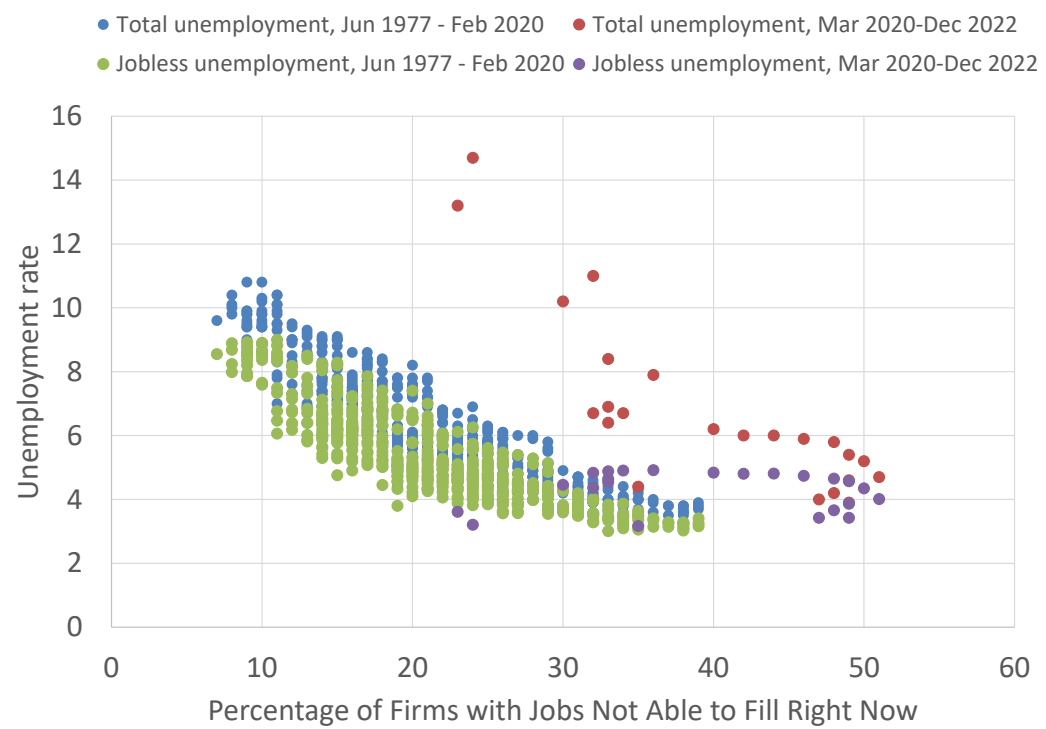

(b) Unemployment rate and Percentage of Firms with Jobs Not Able to Fill

Figure 10: Unemployment and Percentage of Firms with Jobs Not Able to Fill Right Now

Note: The series of the Percentage of Firms with Jobs Not Able to Fill Right Now are from the National Federation of Independent Business Research Foundation obtained from the Conference Board. Data through January 2022. 
unemployment in the CPS may change. During a course of unemployment, a temporaryunemployed individual might receive an indication of losing their job permanently, and become a jobless unemployed. Conversely, the unemployed who were laid off without an indication of recall might receive a signal of an upcoming recall and become a temporary-layoff unemployed. Recall expectations can change back and forth, depending on the additional information about the shock and and individual probability of recall. The distinction between temporary-layoff and jobless unemployment based on expectation of recall is meaningful because expectations inform actions. ${ }^{9}$ In Section 7 , we discuss the social costs of the two kinds of unemployment, which is more closely connected to the outcome of recall after the fact.

Not all individuals on temporary layoff return to their previous jobs. Some may become jobless unemployed, find new jobs, or leave the labor force. Our evidence on higher workfinding rates of the individuals in temporary-layoff versus jobless unemployment in Section 5 indirectly suggests higher recall rates among the temporary-layoff group. But we do not know whether the unemployed who become employed go back to their previous employers, because the CPS does not contain information that would allow tracking this. In this section, we review evidence from other studies that use alternative data showing that, at the onset of the 2020 pandemic, firms laid off a large number of workers with expectation of recall, and a large number of these workers were indeed recalled.

\subsection{Measuring the expectation of recall from employer data}

We supplement the CPS data on expectation of recall with results from employers, who may have more accurate information about the nature of layoffs than the workers in the survey.

Kudlyak and Wolcott (2020) study data on mass layoffs from the notices under the Federal Worker Adjustment and Retraining Notification Act (WARN). They report that, for example, temporary layoffs make up 87 percent of all mass layoffs and plant closures reported under WARN since the week of March 11 in the states of New York, Washington and California. For New York and Washington their data go back to the early 2000s and allow comparing the 2020 pandemic to the 2007-09 recession. During the 2007-09 recession, the rise in the WARN mass layoffs was entirely from layoffs without expectation of recall, while the 2020 spike in the WARN mass layoffs is entirely from temporary layoffs.

Mass temporary layoffs serve as a signal that firms have high expectations of recall. For example, Nekoei and Weber (2020) show that probability of recall increases with share of temporary layoffs in pre-pandemic data from Austria. Specifically, they find that the

\footnotetext{
${ }^{9}$ For example, Nekoei and Weber (2020), using pre-pandemic administrative data from Austria, show that the behavior of unemployed individuals who were laid off with expectation of recall changes abruptly at a date when there is a change in recall expectations, either at the expected hiring date or at the date when former coworkers are recalled by the previous employer.
} 
likelihood of a laid-off worker to be rehired by their previous employer increases with the share of temporary layoffs in their layoff cohort, both for those who were laid off with and without expectation of recall.

Additional evidence from firms on the nature of layoffs comes from the Survey of Business Uncertainty, a monthly panel survey developed and fielded by the Federal Reserve Bank of Atlanta in cooperation with Chicago Booth and Stanford. Using the survey data, Barrero, Bloom and Davis (2020) document that the coronavirus shock caused gross staffing reductions equal to of 14.9 percent of employment reduction between March 1 and midMay, and that temporary layoffs and furloughs account for 77 percent of these gross staffing reductions. ${ }^{10}$

Using weekly administrative payroll data from ADP, the large U.S. payroll processing company, Cajner, Crane, Decker, Hamins-Puertolas and Kurz (2020a) find that temporary layoffs constituted about two-thirds of the decline in paid employment in the ADP firms at the onset of the pandemic.

The data from firms confirm the conclusions from the CPS that the majority of layoffs at the onset of the pandemic were expected to be temporary.

\subsection{Recalls before the pandemic}

In pre-pandemic data, Katz and Meyer (1990), analyzing a sample of UI recipients in Missouri and Pennsylvania from 1979 to 1981, found that 72 percent of UI recipients who initially expected to be recalled were actually recalled, and 13 percent of those who ex ante did not expect recalls were recalled. Nekoei and Weber (2015), using administrative data from Austria on hiring promises and expected hiring dates recorded by the employment office for all job separations that occurred between 2004-2013, found that 42 percent of all separations into unemployment are temporary layoffs. They also find that 58 percent of temporary layoffs and 19 percent of other job loss are recalled within a year after separation, which implies a 35 percent recall rate of all separations into unemployment. Fujita and Moscarini (2017), using data from the Survey of Income and Program Participation, documented that 20 percent of permanently separated workers are eventually recalled by their last employer. Overall, they found that 40 percent of the employed workers who separate into unemployment return, after the jobless spell, to their last employer.

\footnotetext{
${ }^{10}$ Though the BLS does not use the term furlough, it is generally understood to be paid or unpaid leave from a job with an understanding that the worker will be recalled.
} 


\subsection{Recalls in the pandemic}

\subsubsection{Information content of declared recall likelihood}

Using data on unemployment insurance claimants in California, Bell et al. (2021) report that of the claimants who entered the California UI system during the second quarter of 2020 and were "fully separated" from their employer (not just working reduced hours), $51 \%$ of those who initially expected to be recalled and $30 \%$ of those who did not report they expected to be recalled were recalled to their prior employer by the end of 2020 (p.18). Bell et al. (2021) report the overall recall rate for this period at $45 \%$.

Bartik et al. (2020) use daily work records compiled by Homebase, a private sector firm that provides time clocks and scheduling software to mostly small businesses, linked to a survey answered by a subsample of Homebase employees. They study the March-April contraction and the April-May recovery. They find that workers who believed it was likely they would be rehired were 17 percentage points more likely to have been rehired relative to other workers in the same industry and state who believed a rehiring was unlikely. Similarly, workers who had been told by their employers that they would rehired were 26 percentage points more likely to be rehired than those who had been told they would not be rehired.

\subsubsection{Evidence on recalls without conditioning on expectation}

Some studies provide evidence of high share of recalls among new hires, without conditioning on stated expectation of recall.

Cajner, Crane, Decker, Grigsby, Hamins-Puertolas, Hurst, Kurz and Yildirmaz (2020b), using weekly, anonymized administrative payroll data from ADP, measure the evolution of the U.S. labor market during the first three months of the global COVID-19 pandemic and show that worker recall has been an important component of initial employment gains for both re-opening and continuing businesses. They show that about two-thirds of the 5.5 percentage points employment growth between April 25th and May 30th of 2020 was due to employment gains in continuing firms and the rest-due to employment increases in firms that re-opened. Seventy percent of re-entering firms (employee weighted) had their new workforce comprised of at least $90 \%$ employees who worked in the firm in early February, and that hardly any firms reenter without having their workforce comprised of at least half workers who were with the firm in early February. They also show that $65 \%$ of firms grow at least in part by recalling existing workers, and almost $10 \%$ of continuing firms hired exclusively from recall. Kurmann, Lale and Ta (2021), using data from Homebase, find that the recall rate, measured as recalls divided by the total of recalls and new hires, averages about $55 \%$ for 2019 and rises as high as 85\% in mid-April 2020. Ganong, Greig, Liebeskind, Noel, 
Sullivan and Vavra (2021), using a dataset of bank account transactions from the universe of Chase customers from January 2019 through October 2020, measure employment recall from direct deposits into individual accounts. They do not have a measure of expectation of recall but instead report the share of recalls among the unemployed who return back to work. They find that in January and February, about 21 percent of unemployment exits reflected recall to a prior employer; in May this share peaked at 75 percent and fell to 50 percent by October.

\section{Social Costs of Temporary-Layoff and Jobless Un- employment}

We note that, in the regime created by a pandemic, total unemployment retains its social significance even though a high fraction of the unemployed have retained their jobs. Both a temporary-layoff unemployed person and a jobless unemployed person are not working despite a likely inclination to work. There is a gross social loss of the output the worker would have produced while at work, netted against the value the worker can find by productive or enjoyable use of the time freed up by not working. Thus, the social cost of a month of temporary-layoff unemployment is at least approximately the same as the cost of a month of jobless unemployment.

On the other hand, because monthly work-finding rates are substantially higher for those in temporary-layoff unemployment than those in jobless unemployment, the social cost of a layoff with recall prospect is typically well below the social cost of a layoff without that prospect. First, this is because the expected spell of lost productivity is so much shorter. And, second, the job-finding rate of a worker in jobless unemployment understates the expected duration back to a job with productivity equal to the earlier job, because the first job or two may be interim jobs, less productive than the job that the worker eventually settles into. For example, Katz and Meyer (1990) find that recall predicts more favorable wage outcomes. Nekoei and Weber (2015) find that laid-off workers who are recalled experience shorter jobless periods relative to job switchers, and do not experience any wage loss.

Put differently, the worker in temporary-layoff unemployment has a good chance of returning to a position up the job ladder, while the worker in jobless unemployment drops to the bottom of the ladder (unless they are recalled). In Hall and Kudlyak (2021), we calculate the effective exit rate from unemployment, which is lower than the individual monthly exit rate from unemployment. Those individual exits are frequently temporary departures to the labor force or short-term jobs, and are then followed by additional spells of unemployment, 
as described in Hall and Kudlyak (2019). Short-term jobs are an important part of the job-finding process, as studied earlier in Hall (1995).

The distinction between temporary-layoff and jobless unemployment matters for social insurance policies. A typical concern of unemployment insurance benefits is moral hazard issues related to the effect of the benefits on job search. When a large fraction of unemployment is expected recall and not searching, the moral hazard effects are muted. For example, Ganong et al. (2021) incorporate recalls and high costs of job search in a model of the pandemic labor market and find that job search is minimally affected even when replacement rates increase substantially. Giupponi et al. (forthcoming) provide an in-depth analysis of the relative welfare effects of unemployment insurance and labor hoarding subsidies through short-time-work programs during the pandemic.

\section{Concluding Remarks}

A pandemic can trigger a severe recession, with a higher percentage of workers inactive than in the worst past recessions and a corresponding huge drop in output. Fortunately, the subsequent decline in unemployment in the pandemic was much more rapid than in past recessions.

The evidence is reasonably clear that there are two basic kinds of unemployment behind these developments. The shutdown of major sectors of employment led many employers to idle their workers, but to indicate to them that they should plan to be recalled to their jobs. Temporary-layoff unemployment, previously a sideshow in labor dynamics, became the bigger component of total unemployment almost overnight. Soon, temporary-layoff unem-

ployment began to decline, replaced in small part by a rise in jobless unemployment. Total unemployment receded much faster than in earlier recessions.

Tightness in the labor market, revealed by the job-finding rate for active, jobless unemployed individuals, declined early in the pandemic, but not to typical recession levels, and then rose to pre-pandemic levels. 


\section{References}

Barrero, Jose Maria, Nick Bloom, and Steven J. Davis, "COVID-19 Is Also a Reallocation Shock," Brookings Papers on Economic Activity, 2020, Summer, 329-383.

Bartik, Alexander W., Marianne Bertrand, Feng Lin, Jesse Rothstein, and Matt Unrath, "Measuring the Labor Market at the Onset of the COVID-19 Crisis," Brookings Papers on Economic Activity, 2020, Summer, 239-326.

Bell, Allex, Thomas J. Hedin, Roozbeh Moghadam, Geoffrey Schnorr, and Till Von Wachter, "An Analysis of Unemployment Insurance Claims in California During the COVID-19 Pandemic," Policy Report June 30, 2021, California Policy Lab 2021.

BLS, "Frequently Asked Questions: The Impact of the Coronavirus (COVID-19) Pandemic on The Employment Situation for April 2020," 2020. Available at https://www.bls.gov/cps/employment-situation-covid19-faq-april-2020.pdf.

Brown, Laura and Christopher Ferrall, "Unemployment Insurance and the Business Cycle," International Economic Review, 2003, 44 (3), 863-894.

Buera, Francisco J., Roberto N. Fattal-Jaefz, Hugo Hopenhayn, P. Andres Neumeyer, and Yongseok Shin, "The Economic Ripple Effects of COVID-19," Working Paper 28704, National Bureau of Economic Research 2021.

Cajner, Tomaz, Leland D Crane, Ryan A Decker, Adrian Hamins-Puertolas, and Christopher Kurz, "Tracking Labor Market Developments during the COVID-19 Pandemic: A Preliminary Assessment," Discussion Paper 2020-30, Federal Reserve Board Finance and Economics Discussion Series 2020.

, Leland D. Crane, Ryan A. Decker, John Grigsby, Adrian Hamins-Puertolas, Erik Hurst, Christopher Kurz, and Ahu Yildirmaz, "The US Labor Market during the Beginning of the Pandemic Recession," Brookings Papers on Economic Activity, 2020, Summer 2020 (Special Edition), 3-33.

Card, David and Phillip B. Levine, "Unemployment Insurance Taxes and the Cyclical and Seasonal Properties of Unemployment," Journal of Public Economics, 1994, 53 (1), $1-29$.

Chodorow-Reich, Gabriel and John Coglianese, "Projecting Unemployment Durations: A Factor-Flows Simulation Approach with Application to the COVID-19 Recession," Journal of Public Economics, 2021, 197 (104398). 
Feldstein, Martin, "Temporary Layoffs in the Theory of Unemployment," Journal of Political Economy, 1976, 84 (5), 937-958.

Forsythe, Eliza, Lisa B. Kahn, Fabian Lange, and David G. Wiczer, "Searching, Recalls, and Tightness: An Interim Report on the COVID Labor Market," Working Paper 28083, National Bureau of Economic Research 2020.

Fujita, Shigeru and Giuseppe Moscarini, "Recall and Unemployment," American Economic Review, 2017, 107 (12), 3875-3916.

Gallant, Jessica, Kory Kroft, Fabian Lange, and Matthew Notowidigdo, "Temporary Unemployment and Labor Market Dynamics During the COVID-19 Recession," Brookings Papers on Economic Activity, 2020, Fall, 167-216.

Ganong, Peter, Fiona Greig, Max Liebeskind, Pascal Noel, Daniel M. Sullivan, and Joseph Vavra, "Spending and Job Search Impacts of Expanded Unemployment Benefits: Evidence from Administrative Micro Data," Working Paper 2021-19, The Becker Friedman Institute for Economics at the University of Chicago 2021.

Gertler, Mark, Christopher Huckfeldt, and Antonella Trigari, "Temporary and Permanent Layoffs over the Business Cycle: Evidence, Theory, and an Application to the Covid-19 Crisis," Working Paper, Cornell University 2021.

Giupponi, Giulia, Camille Landais, and Alice Lapeyre, "Should We Insure Workers or Jobs During Recession?," Journal of Economic Perspectives, forthcoming.

Gregory, Victoria, Guido Menzio, and David Wiczer, "Pandemic Recession: L or VShaped?," Quarterly Review, 2020, 40 (1).

Hall, Robert E., "Lost Jobs," 1995, (1), 221-273.

and Marianna Kudlyak, "Job-Finding and Job-Losing: A Comprehensive Model of Heterogeneous Individual Labor-Market Dynamics," Working Paper 2019-05, Federal Reserve Bank of San Francisco 2019. and __ "The Inexorable Recoveries of US Unemployment," Working Paper 28111, National Bureau of Economic Research 2020.

and __ , "Why Has the US Economy Recovered So Consistently from Every Recession in the Past 70 Years?," NBER Macro Annual, 2021, 36. 
Hedin, Thomas J., Geoffrey Schnorr, and Till Von Wachter, "An Analysis of Unemployment Insurance Claims in California During the COVID-19 Pandemic," Policy Report June 11, 2020, California Policy Lab 2020.

Katz, Lawrence and Bruce Meyer, "The Impact of the Potential Duration of Unemployment Benefits on the Duration of Unemployment," Journal of Public Economics, 1990, 41 (1), $45-72$.

Kudlyak, Marianna and Erin Wolcott, "Pandemic Layoffs," Working Paper, Middlebury College 2020.

Kurmann, Andre, Etienne Lale, and Lien Ta, "The Impact of COVID-19 on Small Business Dynamics and Employment: Real-time Estimates With Homebase Data," Working Paper, Drexel University 2021.

Lee, Sang Yoon, Minsung Park, and Yongseok Shin, "Hit Harder, Recover Slower? Unequal Employment Effects of the COVID-19 Shock," Review, 2021, 103 (4).

Leyva, Gustavo and Carlos Urrutia, "Informal Labor Markets in Times of Pandemic: Evidence for Latin America and Policy Options," Working Paper 2021-21, Banco de Mexico 2021.

Nekoei, Arash and Andrea Weber, "Recall Expectations and Duration Dependence," American Economic Review: Papers Proceedings, 2015, 105 (5), 142-146.

_ and _ _ , "Seven Facts about Temporary Layoffs," Discussion Paper 14845, CEPR 2020.

Ratner, David, "Unemployment Insurance Experience Rating and Labor Market Dynamics," 2014. Federal Reserve Board, Working Paper No. 2013-86.

Shimer, Robert, "Reassessing the Ins and Outs of Unemployment," Review of Economic Dynamics, 2012, 15 (2), 127-148.

Topel, Robert H., "On Layoffs and Unemployment Insurance," American Economic Review, 1983, 73 (4), 541-559.

U.S.Census, "Current Population Survey Interviewing Manual.," CPS250 U.S. DEPARTMENT OF THE CENSUS, U.S. CENSUS BUREAU, June.https://www.census.gov/programs-surveys/cps/technicaldocumentation/methodology/interviewer-s-manual.html, 2013. 
Weidner, Justin and John C. Williams, "What Is the New Normal Unemployment Rate?," FRBSF Economic Letter, 2011, (2011-05). 